\title{
THE OPTIMIZATION OF THE METHOD FOR SYNTHESIS OF HYDROTREATING CATALYSTS
}

\author{
Ozoda Abdullaevna Salikhova \\ Candidate of Technical Sciences, Associate Professor of the Department of Organic Chemistry and \\ Heavy Organic Synthesis, Tashkent Institute of Chemical Technology, Tashkent, Uzbekistan \\ Shakhzod Murodovich Makhmudov \\ Assistant of the Department of Organic Chemistry and Heavy Organic Synthesis, Tashkent Institute of \\ Chemical Technology, Tashkent, Uzbekistan
}

Azim Eshmurodovich Yangibayev

Independent Researcher, Assistant of the Department of General Chemistry, National University named after Mirzo Ulugbek, Tashkent,Uzbekistan

Article DOI: https://doi.org/10.36713/epra4096

\begin{abstract}
Nowadays the standards for sulfur content in different countries provide for a significant reduction of the indicator to 10 ppm for the gasoline- the raw material for catalytic reforming and 0,01\% by weight. Restriction of the total content of aromatic hydrocarbon (no more than 20\%), replaced by standards of polycyclic aromatic hydrocarbons (no more than 6 $10 \%$ ) and cetane number (45 and higher). This article outlines the development of optimization of the method for synthesis of hydrotreating catalysts. The main purpose of this article is consideration, mainly by the composition of the developed catalyst, of the ways of their modification by additional components, changing the number of active components, modification of the porous structure of the carrier through the synthesis of special types of aluminum oxide with a specified pore distribution by radius or inserting the zeolite component, changes in the conditions of thermal activation of catalysts. One of the main trends in the development of hydrotreating catalysts is their modification by different additives, for example: phosphorus, alkali element, zinc, tin, germanium, copper, uranium, etc.
\end{abstract}

KEYWORDS: activity of industrial catalyst, impregnation by solutions, carrier modification, dispersion of nickel on aluminum oxide.

\section{INTRODUCTION}

The scientific and technical revolution initiated the rapid growth in the 20th century in sphere of industry and transport, consequently it led to the sharp deterioration of environmental condition in many parts of the world. One of the most significant sources of environmental and atmospheric pollution is distillate fuel, which is cleaned from sulfur and other components insufficiently. In the middle of 20th century the use of fuel containing sulfur was restricted in some industrial countries. Therefore, this led to the creation and developing of hydrogenating process. Such countries like United States, Japan, and other European countries put into operation large hydrotreating installations for the production of fuel with a sulfur content of $0,2-0,3$ by weight. However, these standards are insufficient nowadays, and also the requirements of quality have become much more stringent.

Nowadays, the Ferghana refinery produces the diesel fuel with the fuel content not higher than $0,05 \%$ by weight. Aluminum-platinum-rhenium catalysts are used in the process of reforming on industrial installations of Bukhara Oil Refinery and Ferghana Oil Refinery. These catalysts work successfully in reforming processes in that case if the sulfur content is not more than $1,0 \mathrm{ppm}$ and practically does not contain acids. Usually, the sulfur content in the raw material of the reforming is $0,5 \%$. Hydrotreating of sulphurous and 
nitrogenous compounds is carried out in two stages in the presence of aluminum-nickel-cobalt-molybdenum catalyst with a size of $1,6 \mathrm{~mm}$. Catalyst contains Co 0,05, Ni - 4,2 and $\mathrm{Mo}-11.3 \%$. Raw materials with boiling limit of $55-440{ }^{\circ} \mathrm{C}$ hydrogenate in the first stage at the temperature of $385-415^{\circ} \mathrm{C}$, the reaction products are divided into liquids and gas phases, which contain hydrogen and gasoline fraction, in the next second stage they hydrogenate at the temperature of $330-370{ }^{\circ} \mathrm{C}$. The diesel fraction is hydrogenated in the presence of catalysts, without noticeable changes in their group and fractional composition, at the temperature of 350 $400^{\circ} \mathrm{C}$, pressure of 3-6 $\mathrm{MPa}$, volumetric feed rate of 2-5 hours- 1 and the circulation of hydrogen-containing gas $200-600 \mathrm{~m}^{3} / \mathrm{m}^{3}$ of raw materials. The degree of hydrodesulfurization is $85-95 \%$. Mercaptans $(86 \%)$, sulfides $(86 \%)$, disulfides $(88 \%)$ are the most completely removed. In this case catalysts are able to work about 46 years [3].

Depending on the type of the raw material, the activity of the used catalyst and the process conditions hydrogen consumption in the hydrotreating process, diesel fractions range from $0,16 \%$ to $0,45 \%, 50 \%$ of which is spent on hydrogenation of sulfur compounds. The pressure, temperature and hydrogen influence on the depth and the speed of hydrogenating reaction of sulfur compounds. [4].

In the development of work on selecting the optimal synthesis option of hydrotreatment catalyst samples were synthesized, where active components were applied by impregnation method to the calcinated at the temperature of $600{ }^{\circ} \mathrm{C}$ during 6 hours aluminum oxide with weight of $0,70 \mathrm{~g} / \mathrm{cm}^{3}$. In this research were investigated the process of influence of the order and sequence of application of active components, solutions, calcination medium at intermediary stages and the amount of molybdenum oxide applied to the catalyst. The catalyst sample which is close by structure to the catalyst of «Union Oil» company. The results of tests of synthesized samples of catalysts and comparison of their characteristics with catalysts, obtained by traditional prescription are shown in the table1.

\section{MATERIALS AND METHODS}

In the development of work on selecting the optimal synthesis option of hydrotreatment catalyst samples were synthesized, where active components were applied by impregnation method to the calcinated at the temperature of $600{ }^{\circ} \mathrm{C}$ during 6 hours aluminum oxide with weight of $0,70 \mathrm{~g} / \mathrm{cm}^{3}$. In this research were investigated the process of influence of the order and sequence of application of active components, solutions, calcination medium at intermediary stages and the amount of molybdenum oxide applied to the catalyst. The catalyst sample which is close by structure to the catalyst of «Union Oil» company. The results of tests of synthesized samples of catalysts and comparison of their characteristics with catalysts, obtained by traditional prescription are shown in the Table 1.

\section{RESULTS AND DISCUSSION}

From the data in the table1, we can see that a single impregnation from a solution of a mixture of active components by calcination at $600{ }^{\circ} \mathrm{C}$ leads to the production of the catalyst, the hydro desulfurizing activity of which practically does not differ from the activity of the catalyst, obtained by co-precipitation with a slightly lower hydrogenating and splitting activity. Samples, obtained by successive impregnation with solutions of each active component, separately with intermediate calcination after application of the first active component also at $600{ }^{\circ} \mathrm{C}$, and final calcination after applying the second component also at $600{ }^{\circ} \mathrm{C}$ showed sharply different activity in thiophene hydrogenolysis reactions.

The catalyst, in the synthesis of which nickel was applied firstly, is characterized by lower hydrodesulfurizing activity than the catalyst obtained by coprecipitation (the conversion of thiophene at the weight rate of the raw material-1,5hours $14,3 \%$ vs $19,0 \%$ ). Hydrogenating activity is much lower. At the same time, the catalyst, in the synthesis of 
SJIF Impact Factor: 6.260| ISI I.F.Value:1.241| Journal DOI: 10.36713/epra2016

ISSN: 2455-7838(Online)

EPRA International Journal of Research and Development (IJRD)

Volume: 5 | Issue: 3 | March 2020 - Peer Reviewed Journal

Table 1

Test results for catalysts modified with different additives

\begin{tabular}{|c|c|c|c|c|c|c|c|c|c|c|c|c|c|}
\hline \multirow{3}{*}{ № } & \multirow{3}{*}{ Catalyst } & \multirow{3}{*}{ Additives } & \multirow{3}{*}{$\%$} & \multirow{3}{*}{$\begin{array}{c}\text { Bulk } \\
\text { weight }(\mathrm{g} / \mathrm{ml}) \\
\left(\mathrm{Al}_{2} \mathrm{O}_{3}\right)\end{array}$} & \multirow{2}{*}{\multicolumn{3}{|c|}{$\begin{array}{c}\text { Conditions for preprocessing of the } \\
\text { catalyst } \\
\text { Calcination } \\
\end{array}$}} & \multirow{3}{*}{$\begin{array}{c}\text { Specific } \\
\text { surface, } \\
\mathrm{m}^{2} / \mathrm{g}\end{array}$} & \multicolumn{3}{|c|}{ The activity indexes of the catalyst } & \multicolumn{2}{|c|}{$\begin{array}{l}\text { Composition of } \\
\text { coke deposits }\end{array}$} \\
\hline & & & & & & & & & \multirow{2}{*}{\begin{tabular}{|c|} 
Thiophene \\
conversion, \%
\end{tabular}} & \multirow{2}{*}{$\begin{array}{l}\text { Hydrogena } \\
\text { tion, \% }\end{array}$} & \multirow[b]{2}{*}{ Splitting, \% } & \multirow[b]{2}{*}{$\mathrm{C}, \%$} & \multirow[b]{2}{*}{$\mathrm{S}, \%$} \\
\hline & & & & & \begin{tabular}{|c|} 
Temperature, \\
oc \\
\end{tabular} & $\begin{array}{l}\text { Time, } \\
\text { hour. }\end{array}$ & $\begin{array}{c}\text { Environme } \\
\text { nt }\end{array}$ & & & & & & \\
\hline 1 & $\mathrm{BF}-2$ & - & - & 0,64 & 620 & 10 & Air & 270 & 16,4 & 0,098 & 0,029 & 0,88 & 1,50 \\
\hline 2 & $\mathrm{BF}-2 \mathrm{~A}$ & - & - & 0,72 & 620 & 10 & Air & 270 & 23,3 & 0,115 & 0,026 & 0,92 & 1,98 \\
\hline 3 & $\mathrm{BF}-24 \mathrm{a}$ & $\mathrm{B}_{2} \mathrm{O}_{3}$ & 4,9 & 0,74 & 550 & 10 & Nitrogen & 237 & 36,2 & 0,141 & 0,028 & 0,57 & 2,13 \\
\hline 4 & $\mathrm{BF}-24 \mathrm{~b}$ & $\mathrm{TiO}_{2}$ & 4,80 & 0,74 & 550 & 10 & Nitrogen & 210 & 38,4 & 0,085 & 0,044 & 0,89 & 2,37 \\
\hline 5 & $\mathrm{BF}-19$ & $\mathrm{~B}_{2} \mathrm{O}_{3}$ & 0,1 & 0,72 & 550 & 10 & Air & 237 & 24,2 & 0,114 & 0,033 & 0,77 & 2,36 \\
\hline 6 & BF -7 & $\mathrm{BaO}$ & 1,5 & 0,64 & 620 & 10 & Air & 201 & 11,6 & 0,095 & 0,039 & 0,50 & 1,57 \\
\hline 7 & $\mathrm{BF}-33$ & $\mathrm{CaO}$ & 0,7 & 0,72 & 620 & 10 & Air & 355 & 19,4 & 0,115 & 0,060 & 1,63 & 2,24 \\
\hline 8 & $\mathrm{BF}-20$ & $\mathrm{Cs}_{2} \mathrm{O}$ & 0,1 & 0,72 & 620 & 10 & Air & 225,0 & 18,0 & 0,130 & 0,028 & 0,88 & 1,58 \\
\hline 9 & $\mathrm{BF}-21$ & $\mathrm{Cs}_{2} \mathrm{O}$ & 0,1 & 0,72 & 620 & 10 & Air & 287 & 19,3 & 0,116 & 0,036 & 0,67 & 2,4 \\
\hline 10 & $\mathrm{BF}-14 \mathrm{~A}$ & $\mathrm{ZnO}$ & 5 & 0,72 & 620 & 10 & Air & 309 & 12,6 & 0,086 & 0,083 & 2,78 & 0,76 \\
\hline 11 & $\mathrm{BF}-13 \mathrm{~A}$ & $\mathrm{~B}_{2} \mathrm{O}_{3}$ & 4,0 & 0,74 & 550 & 10 & Nitrogen & 237 & 43,0 & 0,123 & 0,028 & 0,90 & 1,27 \\
\hline 12 & $\mathrm{BF}-30$ & $\mathrm{TiO}_{2}$ & 4,0 & 0,72 & 550 & 10 & Nitrogen & 210 & 48,0 & 0,104 & 0,058 & 0,93 & 1,33 \\
\hline 13 & $B F-13 b$ & $\mathrm{ZnO}$ & 2 & 0,64 & 550 & 10 & Air & 240 & 16,7 & 0,075 & 0,039 & 0,64 & 2,19 \\
\hline 14 & $\mathrm{BF}-8 \mathrm{~A}$ & $\mathrm{BeO}$ & 1,0 & 0,72 & 550 & 10 & Air & 230 & 32,4 & 0,135 & 0,028 & 0,90 & 2,24 \\
\hline 15 & $\mathrm{BF}-8 \mathrm{~B}$ & $\mathrm{BeO}$ & 0,6 & 0,72 & 550 & 10 & Air & 230 & 34,6 & 0,141 & 0,026 & 0,88 & 2,36 \\
\hline
\end{tabular}

Note: in those cases, when the content of $\mathrm{NiO}$ and $\mathrm{MoO}_{3}$ are not mentioned, they should be considered to be equal to $4 \%$ u $14 \%$. 


\section{EPRA International Journal of Research and Development (IJRD) \\ Volume: 5 | Issue: 3 | March 2020 \\ - Peer Reviewed Journal}

which the molybdenum was applied is characterized by significantly hydro-desulfurizing activity (29\%-19\%). Taking into account previously established fact of positive influence of calcination on the activity (at the temperature of $550{ }^{\circ} \mathrm{C}$ instead of $600{ }^{\circ} \mathrm{C}$ ), two samples were synthesized according to the BF-18, but the calcination of the intermediate stage and the final heat treatment was hold at $550{ }^{\circ} \mathrm{C}$. The difference between two synthesized samples was that the calcination at the intermediate stage was hold either in the atmosphere of air (BF-22a) or in a nitrogen atmosphere (BF-22b). As we can see from the data in the table 3.7., reducing the calcination temperature to $550{ }^{\circ} \mathrm{C}$ by using this synthesis technique led to the additional, sharp increase in hydro-desulfurizing activity, and the difference in the medium of calcination at the intermediate calcination stage did not affect on the value of thiophene conversion rate of $40,4 \%$ is $2-2,5$ times higher than on industrial samples of ACM and ANM catalysts $(16 \%$ $20,3 \%$ ) and identical to the conversion rate of the catalyst H-6797, type-21 (40,3\%). The highest hydrodesulfurizing activity was shown by samples, obtained by simultaneous impregnation of active components with ammonia solution of nickel molybdenum at $\mathrm{pH}-8$. As we can see in the table 1, the hydro-desulfurizing activity of all three samples (BF-18a, BF-24a, BF-24b) is at the level of $46,9-48,6$, what is higher than in imported catalyst (BF-25) up to $20 \%$ in the test mode without preliminary sulfurizing resulted the reduction of its activity in comparison with components ( $\mathrm{NiO}-4,0 \%$, $\left.\mathrm{MoO}_{3}-12,5 \%\right)$. However, after pre-desulfurization (hydrogen - hydrogen sulfide). These results indicate that the modification of the carrier (24a and 24b) by using additives can change the interaction with the active phase and enhance the activity of the catalyst. Titanium has been shown to disperse well on the aluminum oxide in the amount $14 \%$. The formation of the surface phase of $\mathrm{TiO}_{2} \cdot \mathrm{AL}_{2} \mathrm{O}_{3}$ occurs only when the content of titanium oxide is $1-6 \%$. Dispersion of the nickel on aluminum oxide, modified by titaniumincreases. Apparently, the stronger interaction with the carrier leads to the higher dispersion of oxides and sulfides of nickel molybdenum and therefore, a higher catalyst activity. Boron also affects the hydrodesulfurizing and hydrodeazotizing the activity of the catalyst, the dispersion of $\mathrm{Mo}$ and $\mathrm{Ni}$ increases on $\mathrm{Y}$ $\mathrm{AL}_{2} \mathrm{O}_{3}$.

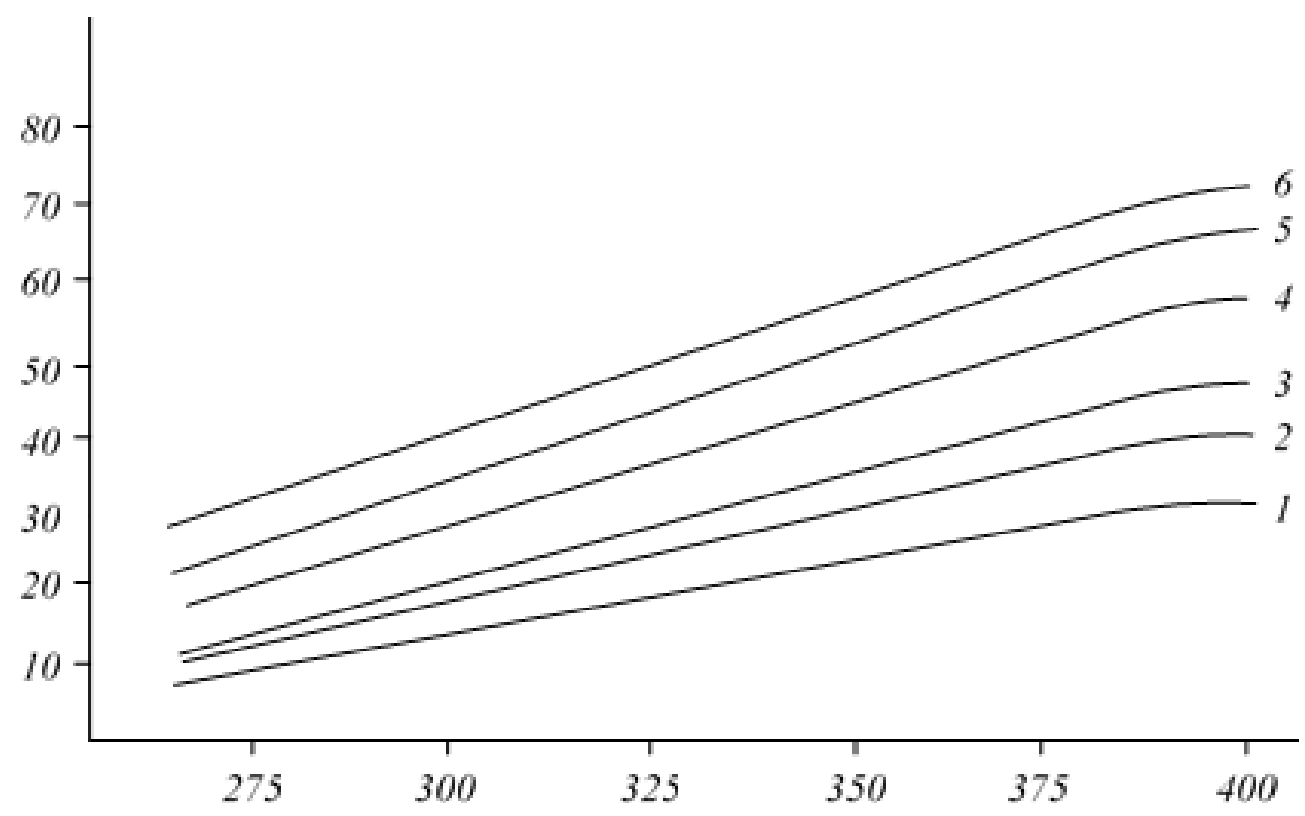

Fig. 1. The dependence on the temperature of the activity of catalysts, synthesized by different ways. $1-B F-17 ; 2-B F-2 a ; 3-B F-18 ; 4-B F-18 a ; 5-B F-246 ; 6-B F-24 a$. 
SJIF Impact Factor: 6.260| ISI I.F.Value:1.241|Journal DOI: 10.36713/epra2016 ISSN: 2455-7838(Online)

EPRA International Journal of Research and Development (IJRD)

Volume: 5 | Issue: 3 | March 2020

- Peer Reviewed Journal

Table 2

Test results of the catalysts, synthesized by different ways

( $T=400$ 0, P=4,0 MPa, V=1.0 h-1)

\begin{tabular}{|c|c|c|c|c|c|c|c|c|c|c|c|}
\hline \multirow{3}{*}{ № } & \multirow{3}{*}{ Catalyst } & \multirow{3}{*}{ The preparation of the catalyst } & \multirow{2}{*}{\multicolumn{3}{|c|}{$\begin{array}{c}\begin{array}{c}\text { Conditions of pre-processing of } \\
\text { the catalyst }\end{array} \\
\text { Calcination }\end{array}$}} & \multirow{3}{*}{$\begin{array}{c}\text { Specific } \\
\text { surface, } \\
\mathbf{m}^{2} / \mathrm{g}\end{array}$} & \multicolumn{3}{|c|}{ The activity indexes of the catalyst } & \multicolumn{2}{|c|}{$\begin{array}{l}\text { Composition } \\
\text { of coke } \\
\text { deposits }\end{array}$} \\
\hline & & & & & & & \multirow{2}{*}{$\begin{array}{l}\text { Thiophene } \\
\text { conversion, } \\
\%\end{array}$} & \multirow{2}{*}{$\begin{array}{c}\text { Hydro- } \\
\text { genation, } \\
\%\end{array}$} & \multirow{2}{*}{$\begin{array}{l}\text { Splitting, } \\
\%\end{array}$} & \multirow[b]{2}{*}{ C, \% } & \multirow[b]{2}{*}{$\mathrm{S}, \%$} \\
\hline & & & $\begin{array}{l}\text { Tempera- } \\
\text { ture, } \mathrm{o} C\end{array}$ & $\begin{array}{l}\text { Time, } \\
\text { hour }\end{array}$ & $\begin{array}{c}\text { Environ- } \\
\text { ment }\end{array}$ & & & & & & \\
\hline 1 & 2 & 3 & 4 & 5 & 6 & 7 & 8 & 9 & 10 & 11 & 12 \\
\hline 1 & BF-2a & Content (bulk weight $\mathrm{Al}_{2} \mathrm{O}_{3}-0,70$ ) & 600 & 10 & Air & 245 & 19,0 & 0,172 & 0,031 & 1,62 & 2,25 \\
\hline 2 & BF-9a & Impregnation(bulk weight $\mathrm{Al}_{2} \mathrm{O}_{3}-0,70$ ) & 600 & 10 & Air & 107 & 18,3 & 0,158 & 0,017 & 1,17 & 4,07 \\
\hline 3 & BF-17 & $\begin{array}{l}\text { In the calcination } \mathrm{Al}_{2} \mathrm{O}_{3}, \mathrm{Ni} \text { is applied,dried,calcinated in } \\
\text { air at } 60{ }^{\circ} \mathrm{C}, \mathrm{Mo} \text { is applied, dried. }\end{array}$ & 620 & 10 & Air & 169 & 14,3 & 0,115 & 0,038 & 0,26 & 2,70 \\
\hline 4 & BF-18 & $\begin{array}{l}\text { In the calcination } \mathrm{Al}_{2} \mathrm{O}_{3}(0,70) \mathrm{Mo} \text { is applied,dried, } \\
\text { calcinated at } 600{ }^{\circ} \mathrm{C} \text { in the air } \mathrm{Ni} \text { is applied, } \mathrm{Ni}\left(\mathrm{NO}_{3}\right)_{2} \\
\text { dried }\end{array}$ & 620 & 10 & Air & 170 & 29,0 & 0,137 & 0,036 & 0,84 & 3,12 \\
\hline 5 & BF-22A & $\begin{array}{l}\mathrm{Al}_{2} \mathrm{O}_{3}(0,70) 550^{0} \text { in the air, impregnation- } \mathrm{Ni}\left(\mathrm{No}_{3}\right)_{2} \\
\text { dried. }\end{array}$ & 550 & 10 & Nitrogen & 139 & 40,4 & 0,185 & 0,017 & 0,49 & 2,21 \\
\hline 6 & BF-22B & $\begin{array}{l}\mathrm{Al}_{2} \mathrm{O}_{3}(0,70) \text { is impregnated byparomolybdate after the } \\
\text { calcination. Calcinated, impregnated by } \mathrm{Ni}, 550{ }^{\circ} \mathrm{C} \text {, } \\
\text { пропитана } \mathrm{Ni}\left(\mathrm{NO}_{3}\right)_{2} \text { dried }\end{array}$ & 550 & 10 & Nitrogen & 140 & 40,4 & 0,164 & 0,022 & 0,36 & 2,10 \\
\hline 7 & H-6797 №21 & & - & - & - & 187 & 40,3 & 0,185 & 0,017 & 1,68 & 0,84 \\
\hline 8 & Al-Co-Mo & & - & - & - & 164 & 20,3 & 0,145 & 0,040 & 0,53 & 2,07 \\
\hline 9 & HOP-463 & & - & - & - & 242 & 440 & 0,129 & 0,031 & 0,87 & 2,41 \\
\hline 10 & BF-25 & By schemeBF-22B, but the content $\mathrm{MoO}_{3}-20 \%$ & 550 & 10 & Nitrogen & 93 & 33,6 & 0,156 & 0,034 & & \\
\hline 11 & BF-23 & $\begin{array}{l}\mathrm{Al}_{2} \mathrm{O}_{3}+\mathrm{SiO}_{2} \text { calcinated at } 600^{0}, 10 \text { hours., impregnated } \\
\mathrm{MoO}_{3}+\mathrm{P}_{2} \mathrm{O}_{5} \text {, calcinated } 550^{0}-8 \text { hours. inN } \\
\text { impregnated } \mathrm{Ni}\left(\mathrm{NO}_{3}\right)_{2} 2 \%-\mathrm{SiO}_{2} ; \mathrm{P}_{2} \mathrm{O}_{5}-4,6 \%\end{array}$ & 550 & 10 & Air & 114 & 44,0 & 0,150 & 0,014 & 0,71 & 3,00 \\
\hline 12 & BF-18a & $\begin{array}{l}\text { Calcinated at } 600{ }^{\circ} \mathrm{C} \mathrm{Al}_{2} \mathrm{O}_{3} \text { impregnated by ammonia } \\
\text { solution of nickel molybdate }\end{array}$ & 550 & 6 & Air & 180 & 46,9 & 0,160 & 0,024 & 0,40 & 2,1 \\
\hline 13 & BF-24a & $\begin{array}{l}\text { Calcinated at } 600{ }^{\circ} \mathrm{C} \mathrm{Al}_{2} \mathrm{O}_{3} \cdot \mathrm{B}_{2} \mathrm{O}_{3}-\text { impregnated by } \\
\text { ammonia solution of nickel molybdate }\end{array}$ & 550 & 6 & Air & 210 & 48,6 & 0,185 & 0,115 & 0,42 & 2,2 \\
\hline 14 & BF-24b & $\begin{array}{l}\text { Calcinated at } 600{ }^{\circ} \mathrm{C} \mathrm{Al}_{2} \mathrm{O}_{3} \cdot \mathrm{TiO}_{2}-\text { impregnated by } \\
\text { ammonia solution of nickel molybdate }\end{array}$ & 550 & 6 & Air & 207 & 46,6 & 0,180 & 0,17 & 0,4 & 2,0 \\
\hline
\end{tabular}

(6) 2020 EPRA IJRD | Journal DOI: https://doi.org/10.36713/epra2016 | www.eprajournals.com |127 | 
The influence of pre-sulfidation on the activity of catalysts. According to the method of determining of hydro-desulfurization activity of hydrotreating catalysts in the reaction of thiophene hydrogenolysis, their preliminary sulfurization is carried out in the medium (hydrogen + hydrogen sulfide). Practically all synthesized and industrial catalysts were tested both without preliminary sulfurization and also after it.

Comparative data by the activity of sulfurized and not sulfurized samples of the catalysts are shown in the table 2. The data of the table 2 shows that the preliminary sulfurization in all cases leads to the increase of the hydro-desulfurizing and hydrogenating activity, splitting activity decreases after sulfurization. However, the degree of increase of the hydrodesulfurizing activity is different for considered catalysts and its determined by the method of their preparation and structure.

The industrial ACM and ANMS catalyst and the sample BF-2(ANM catalyst) after the sulfurization is characterized by the amount of thiophene conversion of GO (70)- catalyst increases from 21,0 to $51,0 \%$ on the sample H-6797, type 21 from 40,3 to 63,5. It means that none of the industrial samples of Russian-made catalysts does not reach the activity index after sulfurization as well as American ones. However, it should be mentioned that the sharp activity increase GO-70(2,5 times), which indicates the importance of starting the essential stage of its preliminary desulfurization with hydrogen sulfide during the procedure of input this catalyst in the hydrotreating process. From a sample of catalysts, including sequential application of active components and intermediate calcination, BF-23, similar in component composition to the prototype of the company «Union Oil» became practically equal to it in activity: the thiophene conversion on these samples is $59,0 \%$ and $63,5 \%$. Thus, the results of preliminary tests of synthesized hydrotreatment catalysts showed the possibility to synthesize the catalysts, which are superior in activity to one of the best foreign samples. It was proved also by test results of newly synthesized catalysts in high -pressure installations in the process of hydrotreating real raw materials. Preliminary reduction at $500{ }^{\circ} \mathrm{C}$ during 6 hours and the next sulfurization led to increase in hydro-desulfurization and hydrogenation activity. The obtained data indicates that the activity of industrial hydrogenating catalysts ACM and ANMS as in the test without preliminary sulfurization with hydrogen sulfide, so after sulfurization in the reaction of thiophen hydrogenolysis is about 2 times lower than the activity of the best foreign sample of «Union Oil» $\mathrm{H}$ 6997, Type 21 . The GO catalyst is an exception, because after the preliminary sulfurization it becomes active by thiophene conversion in the level of $51 \%$, what is close to the activity of the best foreign samples. This may lead to the conclusion about the necessity of installation of the stage of preliminary activation of catalysts for hydrotreating with hydrogen sulfide-containing circulation gas, which is unfortunately absent in modern practice.

\section{CONCLUSION}

From this article we can find out that the modification of the carrier (24a and 24b) using additives can change the integration with the active phase and increase the activity of catalyst, as well as titanium is well dispersed on aluminum oxide in the amount of $14 \%$ of the mass. The formation of the superficial phase of $\mathrm{TiO}_{2} \times \mathrm{AL} 2 \mathrm{O} 3$ occurs only when the content of titanium oxide is 1-6\%.Dispersion of nickel on aluminum oxide, modified by titanium increases, stronger interaction with the carrier leads to the higher dispersion of oxides and sulfides of molybdenum, nickel, the higher activity of the catalyst.

\section{REFERENCES}

1. Agievskiy G. A., Kvashonkin V.I, Kavlova A.I. (1986). The research of oxide predecessors of active structures in Al-Ni-Mo catalysts of extraction separation components. Kinetics and catalysys, Moscow,

№1, pp. 178-185.

2. Ishonxonov N. (2003). Obtaining of ecologically clean hydrosulfite, Tashkent, pp. 201-204.

3. Turobjonov S.M, Abidov B. (2004). Studying of the influence of synthesis conditions of aluminonickelmolybdenum catalyst. Tashkent, №4, pp.136-138.

4. Visotskiy A.B., Lurye M.A., Chenets B.B. (1990). Hydrotreating of heavy crude oil from catalysts containing the ferrosicate. Moscow, T31, №5. pp. 1147-1151 